\title{
Guidance for the family, friends and caregivers of patients with brain injuries
}

$W$

That happens to an already hyperactive mind, when the brain receives an injury? Interestingly, rather than slowing down, it becomes even more hyperactive

"Elizabeth! Stop the train, I wanna get off," she yelled.

"What are you talking about Mom?" her daughter asked, looking totally bewildered.

"My thoughts are travelling at 5000 miles a minute, my mind is on a runaway train," she replied.

Okay, you know what to do, Mama, she told herself. Just breathe in and breathe out, turn on your tranquility waterfall and some soothing classical music. Keep on breathing and for God's sake, remember to exhale.

I am a retired nurse who was forced into early retirement due to a brain injury. I wrote the following during my initial stay in hospital. Recently, I felt annoyed by the lack of understanding among my friends, family and colleagues and decided that maybe I could speak on behalf of brain-injured people. Hence the following guidelines.

\section{Dear everybody!}

This is a plea from your brain injured family member/friend/patient.

Try to accept us the way we are now, we have sustained a major brain injury, be it from a motorbike accident, a brain aneurysm or a bar fight. Whatever got us here, we are not the same as we used to be (as you will have gathered).

Please try to understand that we need peace and quiet and calm and routine, routine, routine!

Take us by the hand and show us what we're supposed to do next, because we don't know, even if we pretend to. Guide us gently from one thing to the next, day after day.

Do not give us any information we do not need, because in our injured brains we can't cope with it! Anything you say and do, can and will be misconstrued because our brains are al-

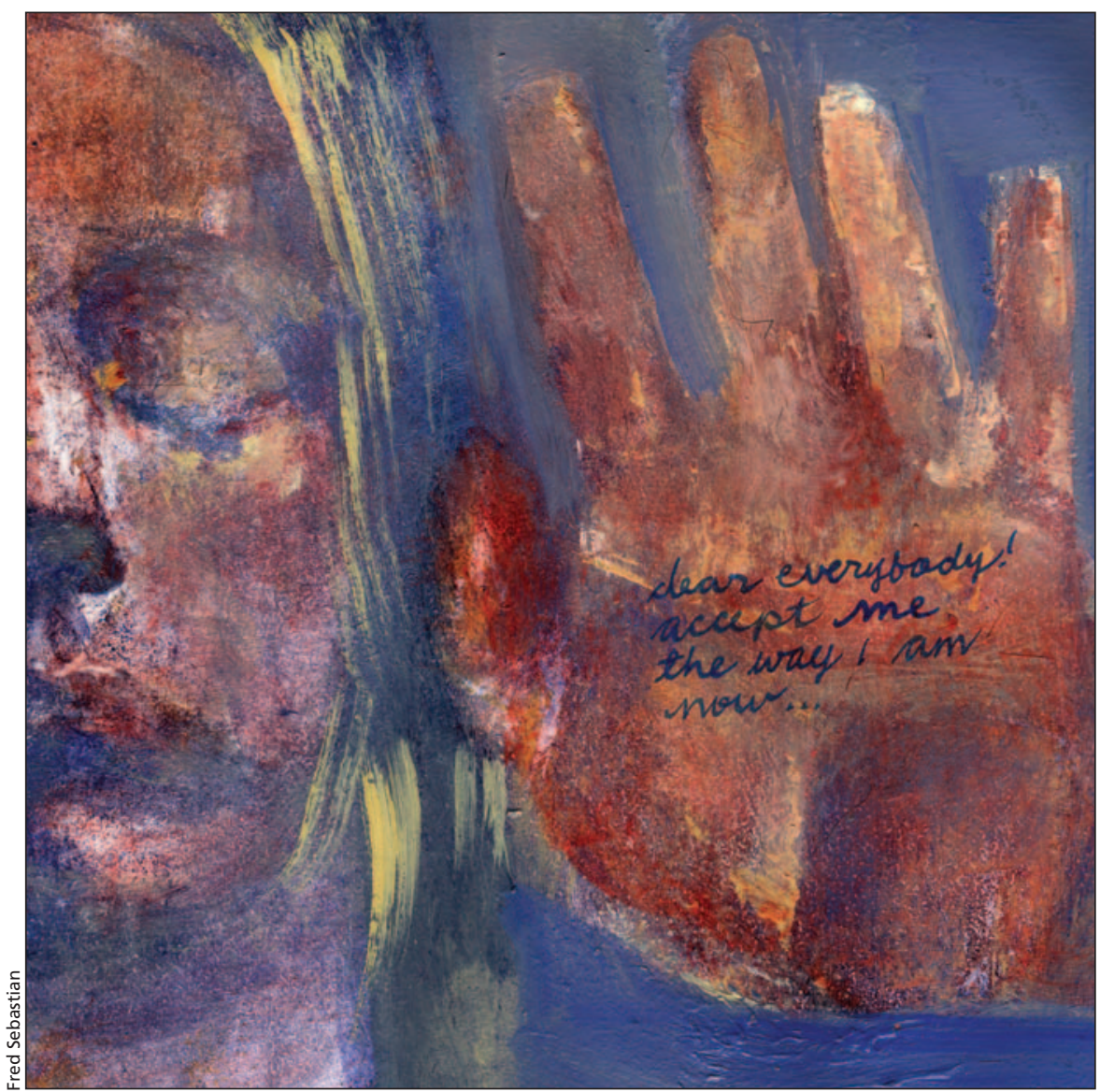

ready in overdrive and we have a hard time processing our thoughts, regardless of what powerful or executive positions we held previously. We may have been in total control of our world and certainly our lives, now we are not and that's scary enough. We have to deal with a brain that's trying to heal as well as deal with everything that crops up. Sometimes that is an impossible task. Already our brains are in overdrive.

Also, it is difficult for us to understand why routine tasks that we used to be able to do blindfolded now leave us bewildered. Any little task is now insurmountable. We get tired and we don't always know what we're supposed to do next. Try to understand the horror of that! We used to be in control of everything, now we're just lost souls relying on you to guide us.
Please do not yell at us; that will only confuse us more. Try to be patient even though you are grieving and feel that you've lost your family member, or their mind, because things are certainly not the way you remember them or wish they were

Do not coerce us into moving or leaving our own environment; moving is a major upheaval at the best of times in anybody's life and it will only confuse us more.

Give us a year or two to try and come to grips with everything and to give our brains a chance to heal. Be kind and be patient because we are like newborn kids having to learn the ropes again.

\section{Inger Harbom Jones BScN RN}

Registered nurse (retired)

Caledon, Ont. 